\title{
FREUD Y LA ESTÉTICA. UNA APROXIMACIÓN
}

\section{Teresa del Conde}

El presente ensayo ha sido elaborado a partir del guión de una conferencia sobre el mismo tema, dictada en la Facultad de Filosofía y Letras durante el ciclo de Homenaje a Sigmund Freud a los cuarenta años de su muerte.

Al igual que algunos autores especializados en historia del arte, como Herbert Read, Ernest Gombrich, Jack Spector y Néstor García Canclini, pienso que esta disciplina encuentra en el sicoanálisis una herramienta utilísima para la comprensión del fenómeno artístico, no sólo por lo que respecta al problema de la creatividad o de la personalidad del artista, sino también porque facilita el análisis de las obras de arte e incluso puede ayudar a elucidar ciertos factores que se encuentran a la base de la aparición de un estilo. Pienso, por ejemplo, que el arte de los pueblos "primitivos", el de la Prehistoria y la Antigüedad y, muy particularmente, las corrientes modernas y contemporáneas a partir del Romanticismo, no pueden ser aquilatadas en toda su dimensión sin el auxilio que proporcionan los postulados sicoanalíticos, y quizá sea posible afirmar que lo mismo puede decirse acerca de cualquier periodo artístico, si bien he querido mencionar únicamente algunos ejemplos que a mi parecer funcionan como paradigmas susceptibles de ser estudiados bajo este enfoque.

A tiempo que afirmo lo anterior de la misma manera creo que ningún análisis estético puede descuidar el estudio histórico, formal e iconográfico de las tradiciones y tendencias artísticas que prevalecen en cada época, porque en ningún caso el arte es sólo autoexpresión que deriva de la introspección. Las expresiones artísticas están determinadas no únicamente por las estructuras inconscientes de sus autores, sino también, $\mathrm{y}$ en forma determinante, por el acceso que el artista tiene a un sinnúmero de códigos que condicionan su vocabulario visual. De este repertorio, tomado de la ideas, la naturaleza, la sociedad y las formas artísticas, el artista extrae lo que para él tiene mayor significado y esta selección, al igual que sus simbolismos privados, sí pone de manifiesto su estructura interna.

El presente escrito no encara tal tipo de problemas sino que constituye el primer esbozo de un trabajo más amplio que abordará 
los principales postulados de la estética freudiana. Dado que el freudismo ha influido no sólo en la aparición de varias corrientes artísticas del siglo $\mathrm{xx}$, sino también en lo que se ha escrito sobre arte a partir de la divulgación de los primeros textos metasicológicos del fundador del sicoanálisis, me ha parecido conveniente intentar en la primera parte de este trabajo una aproximación a la figura de Freud en lo que respecta a su actitud hacia el arte en general y a su aprecio por determinadas obras o periodos artísticos, o sea lo que denotaría su gusto artístico. En la segunda parte del escrito trato de analizar someramente dos obras de Freud que abordan en forma independiente el análisis de una obra determinada. He escogido de sus escritos sobre arte el que dedicó al Moisés de Miguel Angel y de aquellos que versan sobre poesía y literatura el que escribió sobre la Gradiva de Jensen.

A través de lo que a grosso modo podría deducirse de una lectura global del corpus freudiano, incluido el epistolario publicado hasta el momento, puede afirmarse en términos generales que la actitud de Freud ante el arte y especialmente ante los artistas fue mutante y ambigua. En ocasiones parece haber encontrado los origenes que explican el fenómeno de la creatividad, y así lo expresa en forma contundente; pero en otros momentos asegura - a diferencia de sus más incautos seguidores- que no posee la solución a la respuesta planteada por "el dilema del arte". Reiteradamente señaló que "de esto sabemos poco", lo cual, a mi modo de ver, sigue siendo cierto. Esto no quiere decir que sea imposible deducir toda una teoría estética en base a postulados freudianos; pero tal trabajo está aún por hacerse, pese a la ya extensa literatura que existe hoy en día sobre el tema.

Es bien sabido que Freud empleó el método sicoanalítico para explicarse a sí mismo y explicar a los demás todo tipo de fenómenos relacionados con el hombre. De aquí podría deducirse que, en primer lugar, fue muy capaz de gustar de determinadas obras, siempre y cuando pudiera encontrax el origen del placer que le producían. Esta tónica constituye el punto de partida con el que aborda sus análisis artísticos, ejemplificados a través de varios ensayos suyos. Sin embargo, en no pocas ocasiones tal punto de partida encuentra, en otros escritos de Freud, aseveraciones que se contraponen a to que escribió premeditadamente al respecto. Dichas aseveraciones, hechas $\sin$ un propósito deliberadamente analítico, arrojan mu- 
chas luces sobre sus preferencias artísticas. Citaré a continuación algunos ejemplos.

E1 20 de diciembre de 1883 Freud, de paso por Dresden, visitó el Zwinger para ver las colecciones de pintura. Se sintió cautivado por algunos cuadros y escribió a su novia Martha Bernays lo que sigue:

... Cuando supe que también había allí una Madonna de Rafael, la busqué y finalmente la hallé en una sala en forma de capilla con mucha gente contemplándola en silencio. Seguro que la conoces, es la Madonna Sixtina de Rafael...

Después de describirla acuciosamente tal y como hubiera descrito una escena real, sin emitix juicio alguno, termina diciendo lo siguiente: "La belleza de esta pintura ejerce una fascinación imposible de resistir." 1

En este caso no analiza el origen del encanto que le produce el cuadro, sino que se limita a contraponerlo a cierta Madonna de Holbein, a la que encuentra fea, pero revestida de gran dignidad y humildad, "es digna de ser la reina de los cielos", dice. En contraste con ella, la bellísima adolescente de Rafael es una doncella encantadora que mira al mundo con inocencia y vitalidad. Para Freud, las imágenes son personas que están situadas en un determinado contexto y desde el punto de vista estrictamente estético para pocas mientes en factores de composición, color e iconografía. Para él la Reina de los cielos obviamente no existía como ícono representativo de una realidad espiritual, puesto que aparte de ser judío, no creía en dogmas. Sin embargo, sabe que la Virgen María debe ser representada como una reina $y$, según su criterio, esto era lo que daba validés al cuadro de Holbein, cosa que reconoce, a pesar de que le causó mucho mayor placer la Madonna Sixtina.

En la misma carta dice:

E1 único cuadro que dominó por completo mi ánimo fue el Pago del tributo de Tiziano... la cabeza de Cristo es la única plausible que nos permite imaginar a esta persona. Incluso ahora tuve la impresión de que tenía que creer que este ser fue realmente tan importante, porque

1 Epistolario, t. I. Plaza y Janés, Barcelona, 1970 Carta a Martha Bernays escrita en Dresde el 20 de diciembre de 1883 " 
su representación es tan perfecta. No hay nada divino en ella. Una noble cara humana que - sin ser bella- está llena de sinceridad, profundidad, suave indiferencia y, sin embargo, profunda y arraigada pasión. De no estar todo esto en el cuadro, la fisonomía no existiría. Me hubiera gustado llevármelo, pero había demasiada gente alrededor.

En el caso de la Madonna, admira simplemente la pintura en cuanto bella, y no sería ésta la única vez que le ocurriera lo mismo, pero con El pago del tributo están involucrados varios factores que considero necesario desglosar. Tenemos, según Freud, lo siguiente:

a) La cabeza de Cristo es plausible, o sea puede existir en la realidad, no corresponde a una idealización.

b) Lo es porque no hay nada divino en ella, ya que se trata sólo de una noble cara humana. Como no podía admitir la divinidad de Cristo -aunque sí la hubiese admitido Tiziano, que era muy religioso- en esta pintura, que le atraía inmensamente, tampoco la quiso reconocer en su representación.

c) La cabeza posee sinceridad, seriedad, profundidad, suave indiferencia y arraigada pasión. Las tres características primeras, a mi manera de ver, fueron tomadas por Freud como cualidades positivas en un hombre maduro y las dos segundas, "suave indiferencia y arraigada pasión", preludian un anhelo suyo que habría de realizarse años después mediante su autoanálisis. La arraigada pasión permite la autorrealización a través de una tarea existencial, en cuya trascendencia se cree; pero para que esto pueda llevarse a cabo, se requiere el conocimiento y el sometimiento de las pulsiones a la razón, lo que se manifestaría en un estado de equilibrio expresado en la "suave indiferencia", es decir: en la distancia racional ante lo que se analiza.

d) Pero encontramos también que "sin todo esto (sinceridad, profundidad, etcétera), la fisonomía no existiría", en lo que se percibe la convivencia de opuestos que conforman en el cuadro una "fachada" y en el individuo una personalidad. La fisonomía de Cristo correspondía a su carácter y a través de la representación "perfecta", realizada por un hombre, en este caso Tiziano, se podía concluir que Cristo fue realmente importante, debido al efecto poderoso que causó a sus receptores aun a distancia de siglos. El vehículo-Tizia- 
no- resultó dotado de una capacidad de percepción universal. Pero Freud no se refiere para nada a la importancia del pintor, sino del propio Cristo.

e) Por último encontramos el humor, que para Freud posteriormente se constituyó en modelo de creación artística como puede deducirse de su estudio sobre El chiste y su relación con lo inconsciente. En la conclusión a su comentario sobre este cuadro contrapone un hecho real: el placer que experimenta ante él y que le hace desear su posesión, con la imposibilidad de llevárselo. En vez de lamentarse o de explicar con varios argumentos la brevedad del disfrute de una obra maestra, utiliza un giro rápido e imprevisto, totalmente antisolemne.

Las observaciones contenidas en esta carta nos enfrentan, por tanto, con dos formas de apreciar un producto artístico. En la primera el acento está puesto en el placer que produce la representación per se, y en la segunda ya es posible detectar el tratamiento peculiar con que Freud aborda el análisis estético. Lo toma como un texto - un referente que contiene en sí su explicación-y la lee o la ve como vería a un personaje real.

Podría pensarse que Freud hubiera podido ser un excelente intérprete del significado iconográfico de las obras de arte, ya que el método analítico se presta admirablemente para ello. Pero no veía propiamente iconos, sino en muchas ocasiones sólo síntomas. Por eso ante otro cuadro de Tiziano tan cargado de un significado alegórico como El amor sagrado y el amor profano de la Galería Borghese en Roma, únicamente incluye el siguiente comentario en carta escrita a su familia en septiembre de 1907:

El museo posee lo que probablemente sea el más bello Tiziano: se llama Amor sagrado y amor profano. El título no tiene sentido, cualquier otra cosa que la pintura quiera significar es desconocida, pero es suficiente que sea tan bella. ${ }^{2}$

A propósito de esta aseveración, viene al caso un comentario de Gombrich en el que se expresa que los símbolos para Freud eran temas propios de la sala de consulta y que en una pintura él buscaba

2 Epistolario, t. II. Carta a su familia escrita el 21 de septiembre de 1907. 
belleza. ${ }^{3}$ Esto es cierto sólo en parte, porque en realidan ambos factores solian coexistir en sus apreciaciones. Si bien en un número considerable de textos analizó los símbolos como síntomas, la mayoría de las veces trataba de obras que a la vez le procuraban placer extraanalítico, y cuenta de ello es que no mostró particular interés -salvo en dos excepciones a las que me referiré en breve- por la pintura y la gráfica simbolista, tan en boga en su tiempo y tan apropiada para ser estudiada bajo un ángulo sicológico. No es posible pensar que Freud desconociese a Von Marees, a Klinger o a Von Stuck, artistas muy de moda en su tiempo, cuyas respectivas obras ofrecen un amplísimo arsenal que iconográficamente puede ser puesto en relación con el pathos, la sexualidad y el sueño. Freud no gustó de ellos, y cuando abordó el análisis de un dibujo simbolista, no se refirió para nada al hecho de haber experimentado placer, como en los casos anteriores, lo único que le suscitó la obra en cuestión fue interés. Veamos lo que comenta en 1907 acerca de un grabado perteneciente a la serie de Las tentaciones de San Antonio del ilustrador belga Felicien Rops. La obra, que no se encuentra fechada, fue reproducida junto con otros dibujos de Rops grabados por L. Evely en una publicación de 1897 que posiblemente cayó en manos de Freud:

Un ascético monje se ha refugiado -huyendo seguramente de las tentaciones del mundo- a los pies del Redentor crucificado. Pero la cruz va hudiéndose en sombras y en su lugar aparece radiante la imágen de una bella mujer desnuda, también en actitud crucificada.

En el grabado hay otros motivos que Freud no describe, verbigracia: el "fantasma" de Jesús, convertido casi en un esqueleto, al lado izquierdo de la mujer y la presencia de calaveras que emergen de unas pequeñas nubes, al igual que en otras pinturas y grabados convencionalmente cristianos aparecen querubines. Freud toma del conjunto sólo lo que le es indispensable para apuntalar una hipótesis, anotando en ese mismo texto lo siguiente:

En las fuerzas represivas y hasta su misma íntima esencia es donde se impone, al fin victorioso, lo reprimido. Otros pintores de menor agudeza sicológica han representado, en sus alegorías de la tentación,

3 Ernst Gombrich, Critica a los conceptos estéticos de Sigmund Fieud Editorial Cuervo, Buenos Aires, 1976. 
al pecado irguiéndose con expresión de triunfo junto a la imagen del crucificado. Únicamente Rops le ha hecho ocupar en la cruz el mismo puesto del Redentor; pareciendo saber que lo reprimido surge en su retorno del elemento represor mismo.

Un poco antes ha dicho:

Tal retorno de lo reprimido debe esperarse con especial regularidad, cuando a las impresiones reprimidas se encuentra adherido el sentir erótico del individuo, esto es: cuando lo que ha caído bajo el yugo de la represión, es la vida amorosa. ${ }^{4}$

Rops, por supuesto, no fue el único en conocer o intuir la fuerza del elemento erótico reprimido. Esto constituye el sentir de toda una corriente tanto literaria como plástica, algunos de cuyos prototipos serían en literatura, Des Esseintes, el héroe de la novela Au Reburs de K. J. Huysmans y en la plástica los personajes de Franz von Stuck, Max Klinger, Jan Toorop y Gustav Moreau. En México tenemos a Ruelas, donde el tipo de calvarios como el que menciona Freud son bastante frecuentes.

En el comentario anotado, Freud no muestra haberse dejado llevar por un placer estético, sino por un interés sicológico, y prueba de ello es que no sintió necesidad de analizar otras obras de Rops. Le bastó la que tomó como ejemplo para ilustrar un aspecto de su teoría sobre el retorno de lo reprimido.

Este proceder, en el que la obra artística sirve para apuntalat hipótesis, contrasta con sus respuestas de tipo predominantemente sensitivo. Por ejemplo, el año de 1904 Freud visitó la Acrópolis de Atenas, y mucho tiempo después aún recordaba vívidamente ese viaje. Hacia 1924 comentó lo siguiente a Ernest Jones: "Las columnas color ambar de la Acrópolis son las cosas más bellas que jamás vi en mi vida." 5 Siguiendo una costumbre suya, que practicaba siempre que un sitio o un objeto artístico le impresionaba poderosamente, había subido diariamente a la Acrópolis durante su permanencia de una semana en Atenas, dato que quedó registrado en

4 Sigmund Freud, "El delirio y los sueños en la Gradiva de Jensen", en Obras completas, t. II. Editorial Biblioteca Nueva, Madrid, 1972; también en Editorial Grijalbo, Barcelona, 1977. Esta edición incluye el relato original de Wilhelm Jensen.

5 Ernest Jones, citado por Ernst Gombrich, en Freud y la sicologia del arte. Barral, Barcelona, 1971. 
su correspondencia. Pero salvo el comentario muy posterior, hecho a quien habría de ser su principal biógrafo, no aventuró -que yo sepa- ninguna otra observación acerca de esas ruinas que encontró tan bellas. Por cierto, en 1899, o sea cinco años antes de realizar el viaje en cuestión, Freud había leído con detenimiento la Historia de la civilización griega de Burckhard, y años después dijo a Stefan Zweig que "en realidad había leído más libros sobre arqueología que sobre sicología". 6 lo cual resulta muy natural, puesto que la labor arqueológica para Freud era una metáfora del proceder sicoanalítico, cosa que quedó claramente expresada en su estudio introductorio al famoso "caso de Dora".

Sin embargo en lo personal creo que, cuando veía la Acrópolis, él no buscaba fundamentalmente modelos analógicos, sino "esas gratificaciones sustitutiva que ofrece el arte, que son las que hacen que los hombres puedan reconciliarse con los sacrificios hechos en pro de la cultura". "

A lo largo de casi toda su vida, Freud, emitió hipótesis diversas acerca del posible origen de las dotes artísticas, y a nadie escapa que su interés por la personalidad del artista corre parejo con sus estudios sobre lo que hace posible el proceso de sublimación. Sin embargo, pese a que le intrigaban profundamente los dones que poseían los artistas y en especial los poetas, a quienes respetaba mucho más que a los pintores, la personalidad y el carácter del individuo productor de obras de arte le producía un efecto ambivalente, como veremos a través de las citas que a continuación anoto.

En 1883 afirma que cree que:

Hay una enemistad de carácter general entre los artistas y las personas cuya vida transcurre entre las alternativas de la labor cientifica. Sabemos que ellos, a través de su arte, poseen la llave maestra que abre fácilmente todos los corazones femeninos, mientras que nosotros quedamos mirando impotentes el extraño diseño de la cerradura y tenemos que atormentarnos bastante hasta descubrir una llave apropiada.

Poco tiempo después observa:

6 El dato está tomado de Bernard Urban y Johannes Cremeri, prólogo a $\mathrm{Fl}$ delivio y los sueños..., en la edición de Grijalbo.

7 Sigmund Freud, "El malestar en la cultura", en Obras completas, t. III. 
Sólo en el terreno de la lógica es imposible la coexistencia de cosas contradictorias. En los sentimientos las contradicciones persisten y viven felices una junto a la otra. $Y$ donde menos pueden negarse tales contradicciones es en los sentimientos de los artistas, gente que no tiene oportunidad de someter su vida interior al severo control de la razón. ${ }^{8}$

La expresión "llave maestra que abre (corazones)", ya guarda un simbolismo obviamente sexual a pesar de que en 1883 Freud se encontraba a doce años de distancia de iniciar a través de su propio análisis, el sondeo de los simbolismos sexuales que aparecen en los sueños. La aseveración contiene un dejo de envidia ante el artista. Él, como científico, se sentia en ese momento impotente para descubrir la llave que abriria el extraño (por desconocido), diseño. Cabe aclarar que ninguno de los biógrafos de Freud han descubierto datos que permitan inferir experiencias sexuales prematrimoniales y aunque es más que probable que las haya tenido, lo cierto es que debieron ser sumamente escasas. Freud fue "casto" toda su vida y el año que escribió lo que he anotado acerca de artistas, llaves y corazones, se sentía profundamente inseguro debido a que su novia era cortejada, de manera muy victoriana por supuesto, simultáneamente por un pintor y por un músico.

La ambivalencia ante el axtista no desapareció ni con su avasalladora posesión del objeto amado ni con sus extraordinarios conocimientos sobre la sique humana. Hablando acerca de una de las facetas más interesantes de la vida imaginativa, dice en 1917:

Se trata de la existencia de un camino de retorno desde la fantasía hasta la realidad... Este camino no es otro que el arte. El artista es un introvertido próximo a la neurosis. Animado de impulsos y tendencias extraordinariamente enérgicos, quisiera conquistar honores, poder, riqueza, gloria y amor.

Pero al concluir el mismo texto, cambia de tónica afirmando que:

El verdadero artista sabe dar a sus sueños diurnos una forma que los despoja de aquel carácter personal que pudiera desagradar a los 8 Ernest Jones, Vida y abra de Sigmund Freud, vol. I Paidós, Buenos Aires, 1976. 
extraños y los hace susceptibles de constituir una fuente de goce para los demás. ${ }^{9}$

Esa fuente de goce, según el pensamiento de Freud, no siempre es producida por los más afamados artistas de cada época, o sea a los que representarían L'avant-garde. Por ejemplo, nada hay que permita saber si se percató de la importancia de las innovaciones de Picasso, y ni siquiera hace comentario alguno sobre las pinturas de los impresionistas franceses tan exhibidas y comentadas a principios de este siglo. En cambio sí hay muestra evidente de que los expresionistas alemanes francamente le disgustaban, puesto que así se lo hace saber a su amigo, el pastor protestante y estudiante de sicoanálisis Oskar Pfister, el 21 de junio de 1920. "No tengo paciencia alguna con los lunáticos - dice refiriéndose a los pintores expresionistas- sólo veo el daño que pueden hacer."10

La misma aprensión hacia este tipo de pintura queda puesta de manifiesto en una carta que dirigió a su discípulo Karl Abraham, quien le había enviado como regalo un retrato suyo de mano de un dibujante expresionista.

Querido amigo, recibí el dibujo que pretendidamente representa tu cabeza, es horrible... Yo sé que eres una persona excelente, por lo que estoy todavía más conmovido de que este pequeño defecto en tu carácter, como es tu tolerancia o simpatía por el "arte". (sic) moderno, haya sido castigado tan cruelmente, deja que me olvide de tu retrato para desearte lo mejor para $1929 .{ }^{11}$

Hasta este momento puede pensarse que el gusto artístico de Freud era conservador, y que su paradigma era el arte clásico. Sin pretender realizar una interpretación general que desmienta o reafirme esta suposición, he de referirme a continuación a los objetos artísticos que Freud fue adquiriendo a partir de 1896 y que siguió comprando hasta 1920, logrando conformar un conjunto que constituye una rica colección privada, si no excelente en calidad, sí superior a lo que solía ser común en tal tipo de colecciones. Los

${ }^{9}$ Sigmund Freud, Introducción al sicoanálisis. Alianza Editorial, Madrid, 1969.

10 Sigmund Freud y Oascax Pfister, Correspondencia. 1909-1939. Fondo de Cultura Económica, México, 1966.

11 Epistolario, t. II. Carta a Karl Abraham escrita en Viena el 23 de diciembre de 1922. 
objetos estuvieron distribuidos en vitrinas y armarios en su casa de Berggasse 19 en Viena, y pasaron casi en su totalidad a Maresfield Gardens en Londres, donde pueden verse hoy en día.

He tratado de mencionar las diversas clases de objetos formando conglomerados, con la intención de poner en evidencia la actitud del coleccionista.

Freud poseía pocas obras bidimensionales - pictóricas o gráficassi se comparan éstas con la gran cantidad de piezas escultóricas que llegó a adquirir. Veamos inicialmente cuáles son las primeras.

Reproducción de La lección de Anatomía del profesor Tulp, de Rembrandt. De este mismo artista dos aguafuertes: Judios en el templo y Cabeza de un comerciante, ambos de 1656.

Grabado de El beso de Judas de Durero (1508).

Reproducciones de los frescos de Masolino y Masaccio en la Capilla Brancaci de la iglesia de El Carmen de Florencia, son: La curación de Eneas por San Pedro y La Resurrección de Thabithia. El grabado de Brouillet que representa la Lección del doctor Charcot en La Salpetriere. Dos grabados de Ulbrich: uno representa la esfinge de Gizeh y otro las esculturas funerarias de Abu Simel; otro grabado de Edipo y la esfinge según el óleo de Ingres; una reproducción al óleo de La pesadilla de Fuseli.

Sobre su escritorio tenía una xéplica reducida de El esclavo de Miguel Ángel, que se encuentra en el Louvre. Un contemporáneo de Freud, el pintor Gustave Moreau, había dicho de esta escultura que:

Parece fijarse en un estado de sonambulismo ideal. Es inconsciente de los movimientos que ejecuta, se encuentra absorbida en su sueño a tal grado, que parece transportada a otros mundos.

Respecto a esta parte de la colección se puede interpretar 10 siguiente: la presencia de La lección de anatomía obedecía a un propósito convencional. Casi todos los gabinetes médicos de esa época ostentaban una reproducción de esta obra. Incluso hoy en día es muy frecuente encontrarlas en esos sitios. En cambio los dos aguafuertes y el grabado de Durero obedecen a una convicción de clase. Si la Lección de anatomía afiliaba a Freud a su antigua profesión de médico, las otras tres obras se relacionaban con su fidelidad al pueblo de Israel. Freud fue muy abierto con los "gen- 
tiles" y nunca le gustó pertenecer a ghetto alguno, pero estaba orgulloso de su ascendencia semita.

Las reproducciones de los frescos italianos son casos de curación. El primero posiblemente se refería a una parálisis histérica y el segundo a una catalepsia. La curación se llevó a cabo a través de un healer -San Pedro- que podría haber sido el propio Freud. Respecto al conocido grabado que representa a Charcot induciendo a una enferma al trance hipnótico, hay que tener en cuenta, aparte del tema mismo y del sentido erótico que la composición sugiere, la gran admiración que Freud llegó a sentir por el médico francés, con quien estudió en París el año de 1883, traduciendo después al alemán dos de sus principales trabajos.

La esfinge como reveladora del enigma fue para Freud un símbolo importantísimo. Alguna vez comentó que deseaba ver una inscripción conmemorativa a la puerta de su casa en Viena en la que pudiera leerse: EN ESTE SITIO EL ENIGMA DEL SUEÑO FUE REVELADO AL DOCTOR SIGMUND FREUD. La pesadilla de Fuseli y El esclavo de Miguel Ángel guardan relación con el sueño y la última pieza mencionada, además connota la necesidad de romper cadenas.

También en su escritorio, colocadas de pie y enfiladas, tenía veinte estatuillas de diversa procedencia: egipcias, chinas, griegas y romanas, la mayor parte de ellas funerarias y algunas correspondientes a representaciones de diosas de la fecundidad. Delante de ellas, en sitio más relevante, tenía un escriba chino, al que por cierto saludaba todos los días.

Llegó a poseer un número considerable de piezas egipcias, especialmente sarcófagos, cortados a la altura de los hombros y figurillas talladas en madera o modeladas, procedentes de aquellos Barcos de la muerte como los que existen en casi todas las secciones de los museos dedicadas a arte egipcio. A esto se sumaban varios retratos funerarios del Fayum y vasos griegos y etruscos, algunos espléndidos. Tenía uno de éstos lleno de huesos, y cuando redactó su testamento dispuso que sus cenizas fueran depositadas en uno que apreciaba especialmente.

Entre las piezas escultóricas más valiosas se encuentra el plano frontal de un sarcófago romano que ostenta un relieve que parece referirse a los funerales de Patroclo.

A todo esto se sumaban decenas más de piezas arqueológicas de procedencia diversa y de distintos tamaños, colocadas en vitrinas, 
sobre las mesas, a adosadas a los muros. Ana Freud dijo que a su padre le disgustaban los "huecos" o espacios vacíos, en tal forma que su estudio y el cuarto contiguo se encontraban saturados de objetos y pesadamente alfombrados.

Las piezas no fueron compradas en galerías ni -salvo raras ocasiones- adquiridas por Freud durante sus viajes. El acostumbraba recibir a los marchands en su estudio, y por lo común ya existía un entendimiento previo acerca de lo que él podría seleccionar. Las piezas procedían, en su mayoría, de galerías parisinas y Jack Spector estima que un setenta por ciento de ellas son auténticas. ${ }^{12}$ Varias le fueron obsequiadas, entre ellas la copia de un relieve denominado Gradiva por W. Jensen, que pertenece a la colección Chiaramonti de Roma.

En lo personal he sacado la siguiente deducción. Algunas obras, principalmente las reproducciones de pintura y los grabados, obedecían a un criterio preciso de selección que líneas atrás he intentado interpretar, en tanto que las esculturas, sarcófagos, ánforas funerarias y vasos fueron reunidos con criterio asistemático que respondió integramente a un impulso personal de Freud. Siendo que la proporción de piezas escultóricas es mucho mayor que la de obras bidimensionales, se concluye que este coleccionista sentía una atracción particular por el objeto tangible y volumétrico, que corrobora la aseveración de su biógrafo Jones, cuando éste jerarquiza las aficiones de Freud respecto al arte diciendo que prefería en primer lugar la literatura, a continuación la escultura, luego la arquitectura, en menor grado la pintura y el grabado y al último la música. Por cierto, se ha dicho insistentemente que Freud no disfrutaba de la música, pero lo cierto es que como todo buen vienés, asistía con frecuencia a conciertos. Además le encantaba la ópera, especialmente Mozart, aunque también gustaba de la ópera italiana, si bien dentro de este género su obra preferida era Carmen de Bizet. No hay indicios de que haya tenido predilección por la ópera wagneriana, aunque sí le interesaban los libretos.

Volviendo a la colección, lo que la unifica en buena medida, sobre todo en su parte escultórica, es el origen remoto y no siempre

12 Jack Spector, The Aesthetics of Freud. Mac Graw-Hill Book Company, New York, 1972 . 
detectable de un buen número de piezas. Disfrutaba éstas porque podía utilizarlas para aclararse a sí mismo ciertas ideas, para ilustrar a los demás utilizándolas como ejemplos y también porque podía tocarlas y sentir sus contornos al tenerlas entre sus manos mientras meditaba. Además les prodigaba un cierto tipo de amor, no exento de un toque ritualístico. Ya vimos que saludaba al escriba todos los días y que existían veinte piezas predilectas colocadas de cara a él en su escritorio. Cierto día una de éstas se rompió, y Freud comentó que "había sido sacrificada". Obviamente no podía considerar el movimiento brusco que hizo caer a la pieza colocada a la orilla como un simple accidente $-\mathrm{y}$ posiblemente tenía razónporque casi no se dieron "sacrificios" de este tipo.

Ya habrá podido verse que la temática de la colección está referida a dos temas fundamentales: la muerte y la sepultura. En el contexto interno de este particularísimo coleccionista, la muerte debe tomarse, no como lo que no existe, sino como lo que permanece vivo aun y cuando aparentemente pertenezca al mundo de lo muerto. Sobre lo sepultado nos ilustra el propio Freud:

No existe analogía mejor para la represión que el sepultamiento, pues éste hace inaccesible algo anímico, pero al mismo tiempo lo conserva, lo mismo que Pompeya fue conservada por las cenizas que la sepultaron, de entre las cuales resurgió en las excavaciones. ${ }^{13}$

La segunda parte de este escrito versa, como indiqué al principio, sobre dos textos de Freud deliberadamente avocados al análisis de un producto artístico. El primero de ellos fue escrito en 1907 y el segundo en 1914. Por tanto, son posteriores al modelo de análisis que Freud inauguró a partir de La interpretación de los sueños. A través de las citas textuales que hasta este momento he incluido, el lector habrá comprobado que las observaciones acerca del arte, emitidas por Freud a lo largo de toda su vida, no son privativas de sus análisis estéticos y es conveniente aclarar que un estudio sobre la estética freudiana, que sólo tomase en cuenta los textos acerca del arte o la creatividad, distaría de conformar una visión certera del pensamiento freudiano sobre cuestiones de arte.

Los trabajos de Freud que abordan en forma directa temas rela. cionados con la estética son los que siguen:

13 En El delirio y los sueños... 
Los carácteres sicopáticos en la escena (1905).

El delirio y los sueños en la "Gradiva" de Jansen (1907).

El poeta y la fantasia (1908).

Un recuerdo infantil de Leonardo (1910).

El tema de los tres cofres (1913).

El Moisés de Miguel Ángel (1914).

Algunos tipos de caracteres puestos en evidencia por el sicoanálisis (1915).

Un recuerdo infantil de Goethe en "Poesia y verdad" (1917).

Lo siniestro (1919).

Dostoievski y el parricidio (1928)

Entre todas estas obras, la predilecta de Freud fue el Leonardo y lo era junto con La interpretación de los sueños en el contexto general de su producción. Emest Jones prefería la Gradiva y $E l$ enigma de los tres cofres, pero el consenso del público lector de Freud por lo común se pronuncia por el Leonardo. Yo no me referiré a este ensayo debido a que ha sido el más comentado por la historiografía y la crítica de arte. He elegido $E l$ delirio y los sueños en la "Gradiva" de Jensen y El Moisés de Miguel Ángel siguiendo las preferencias manifestadas por Freud hacia la poesía -él designaba así a todas las obras literarias aunque no fueran poemas- y hacia la escultura.

A principios de 1907 Freud publicó, en una colección que acababa de inaugurar y que lleva por título Trabajos de sicologia aplicada, un pequeño volumen que es el sicoanálisis de una novela. En este ensayo estudia el relato del escritor danés Wilhelm Jensen, publicado en 1903, cuya trama versa sobre los sueños y ensueños de un joven arqueólogo que se enamora de un relieve griego -seguramente el fragmento de una estela funeraria del siglo Iv a. C.- que representa a una doncella caminando ágilmente. De aquí el título de la novela: Gradiva, que quiere decir "la que avanza".

El interés del arqueólogo se centra en el paso elegante y atípico de la figura, uno de cuyos pies forma casi ángulo recto con el plano horizontal. A partir de este elemento, el protagonista, cuyo nombre es Norberto Hannold, forja una serie de fantasías que van tomando un matiz obsesivo hasta que se convence, a través de un sueño, de que la mujer representada falleció el año 79 de nuestra era durante la erupción del Vesubio. A partir del estímulo 
que una mañana le provoca el trino de un pájaro, decide viajar a Italia, sin que sus propósitos conscientes tuvieran como meta Pompeya, sitio que se convierte en punto final y destino oculto de su viaje. Alli encuentra, efectivamente, a una joven idéntica a la representada en el relieve. Sostiene varias entrevistas con ella pensando que puede ser tanto un espíritu como una persona real.

La muchacha de Pompeya en realidad es Zoe Bertgang, una vecina y compañera infantil de juegos suya, en quien él no había vuelto a reparar. La asocia directamente al relieve debido al hecho de que la muchacha camina en forma peculiar. Su confusión crece a tal punto, que la muchacha se da cuenta de lo que le sucede y sigue un doble juego: lo complace personificando a Gradiva y mostrándose como un fantasma, al mismo tiempo que introduce en cada una de las entrevistas que sostienen, ciertos datos sobre su realidad física mediante juegos de palabras ingeniosos que mantienen la ambigüedad en los mensajes. Tal proceder de Zoe-Gradiva, acaba por destruir el equívoco, situando al hombre en la realidad y propiciando el desenlace amoroso.

Jung fue quien llamó la atención de Freud respecto a la analogía entre el proceder de Jensen, que basa su relato en sueños y situaciones delirantes que finalmente ceden ante la posesión del objeto amado, y el proceder sicoanalítico. Tanto a él como a Freud les asaltó la idea de que Jensen podía haber abrevado en La interpretación de los sueños para armar su novela, ya que ésta se estructura en base a material onírico y asociaciones provocadas por ciertos estímulos que reactivan hechos olvidados. Sin embargo, el autor al parecer, no conocía las obras de Freud, al menos así lo atestigua la correspondencia que sostuvieron ambos después de la publicación de Freud sobre la novela. Si las cosas realmente fueron así, se confirma una vez más la idea de que las aportaciones intuitivas de literatos $y$ pintores durante la segunda mitad del siglo $x I x$, constituyen un importante respaldo que antecede a las teorías sicoanalíticas sobre la dinámica del inconsciente y sobre los sueños como vía magna a su acceso. En la introducción a su estudio Freud dice que:

En esta discusión sobre la naturaleza del sueño parecen los poetas situarse al lado de los antiguos, de la superstición popular, del autor de estas líneas y por tanto de La interpretación de los sueños, pues 
cuando hacen soñar a los personajes creados por su fantasía, no sólo se conforman a la cotidiana experiencia de que el pensamiento y la sensibilidad de los hombres continúan vivos en el estado de reposo nocturno, sino que al presentarnos los sueños de sus personajes su intención es precisamente darnos a conocer por medio de ellos los estados del alma de los mismos. Y los poetas son valiosísimos aliados, cuyo testimonio debe estimarse en alto grado, pues suelen conocer muchas cosas existentes entre el cielo y la tierra que ni siquiera sospecha nuestra filosofía.

Pero a diferencia de los sueños que todo individuo tiene y que Freud interpretaba separando aisladamente cada uno de sus elementos, sin dejarse llevar de primera mano por la historia "filmada" que el soñante revela, el poeta, al narrar e interpretar sueños, siempre presta más atención a su contenido manifiesto, o sea al significado global. Conviene asentar algo que seguramente no ha escapado al lector: los sueños inventados por los artistas, sean éstos literatos o pintores, son en realidad ensueños diurnos y por tanto, igualmente susceptibles de ser analizados siguiendo el método freudiano.

Ésa fue la intención inicial de Freud, tal como quedó explicitada en la primera parte de su escrito, intención que rebasó, puesto que no se limitó a analizar los sueños de Norberto Hannold, sino también sus actos fallidos, su "delirio", que por cierto no parece haber sido tan intenso y, sobre todo, sus reacciones a estímulos que a primera vista parecen irrelevantes y que, sin embargo, en el texto original de Jensen están puestos en evidencia. Otro aspecto importante, tanto del relato de Jensen como del estudio de Freud, está conformado por el análisis lingüístico de ciertas palabras. Por ejemplo: Gradiva y Zoe quieren decir lo mismo.

Cabría preguntarse: ¿por qué no se limitó Freud al plan inicialmente concebido, prolongando lo que iba a ser un artículo, hasta que adquirió las dimensiones de un ensayo largo? A mi manera de ver ocurrió lo siguiente: así como el autor de la novcla está presente en la imagen del protagonista, así también Freud se identificó estrechamente con el personaje, con lo que el relato adquirió para él un sentido que en cierta forma reflejaba una parte de su vida.

Hannold se sumió por completo en sus estudios, apartándose de la vida exterior y de los goces que ésta ofrece a la juventud, de 
tal manera que encauzó su existencia hacia su profesión de arqueólogo sin admitir desviaciones, puesto que sólo la arqueología justificaba su paso por la tierra.

$Y$ ya hemos visto que a Freud le apasionaba la arqueología y que consideraba que su método consistía en:

Seguir el ejemplo de aquellos exploradores que, tras largas excavaciones, tienen la dicha de sacar a la luz los inapreciables aunque mutilados restos de la antigüedad. He completado lo incompleto de acuerdo con los mejores modelos que me eran familiares por otros análisis, pero, tal como haría un arqueólogo concienzudo, en ningún caso he omitido señalar dónde mi construcción se yuxtapone a lo auténtico ... ${ }^{14}$

Por otra parte, la vida de Freud fue sumamente parca en cuanto a acontecimientos importantes. Éstos se encuentran marcados, según han señalado sus biógrafos, casi excluivamente por las etapas de su producción y por la trayectoria del movimiento sicoanalítico.

Sin embargo,

la naturaleza - dice Freud- había dotado a Hannold de una cualidad nada científica, que sirve de correctivo a las anteriores: una arrebatadora fantasía, que no se manifestaba tan sólo en sueños, sino también, a veces, en su actividad despierta.

Jensen alude poco a esta manifestación diurna de la fantasía del protagonista. Éste es presentado como un hombre serio, calmo "sentado entre sus muros, sus libros y sus imágenes sin necesitar de otro tipo de relaciones y en cambio eludiendo en lo posible cualquiera de ellas por considerarla una vacua pérdida de tiempo". ${ }^{15}$

Freud insiste en que:

Tal disociación entre la labor intelectual y la fantasía le predestinaba (a Hannold) a acabar en poeta o en neurótico, incluyéndolo entre aquellos hombres cuyo reino no es de este mundo.

Freud siempre creyó que su reino nunca sería de este mundo,

14 Sigmund Freud, Fragmento de análisis de un caso de histeria (Dora) Amorrotu editores, vol, 7. Buenos Aires, 1978.

15 En el relato original de Jensen publicado por Grijalbo. 
y de hecho sus teorías encontraron aceptación muy tardía y en ningún caso unánime. De aquí su preocupación por formar discípulos que continuaran investigando y propagaran su pensamiento. Ni siquiera consideró haber levantado el "edificio" del sicoanálisis, sino únicamente los cimientos y los ladrillos para realizar la construcción.

Freud se consideraba, ante todo, científico y desconfiaba de sus dotes intuitivas. Por eso su conflicto entre la labor científica y la especulación metasicológica, que lo sitúa al lado del artista, ha hecho afirmar a varios autores que sus dotes creativas, más acentuadas que las de muchos novelistas, se encontraban en una lucha dialéctica y continua que implicó gxandes renuncias al placer que proporciona la expresión de la fantasía.

Coincidiendo con Jensen, Freud afirma que Hannold "se trasladó a las pasadas épocas, pero no ya con la ayuda de la ciencia". Cotejemos esta afirmación con el relato del novelista:

Lo que ésta enseña (la ciencia), es una fría concepción arqueológica expresada en un muer to idioma filológico e insuficiente para llegar a la comprensión del alma de las cosas. Aquel que sienta el anhelo de adentrarse en la íntima realidad de Pompeya, habrá de pasar solitario esta ardiente hora meridiana entre los restos del pasado y mirar y oír con algo más de sutil capacidad de percepción que la que proporcionan los ojos y los oídos. Sólo entonces verá despertar de nuevo a los muertos y comenzará Pompeya a vivir ante él.

¿Cuál era la íntima realidad de Pompeya que sólo podía alcanzarse con esa "sutil capacidad"? La metáfora alude a la realidad interior del personaje, que sólo llegó a ella prescindiendo de los métodos que provienen del consciente lógico para dejar paso -siguiendo impulsos extraños e inexplicables - al retorno de lo reprimido. Este tenía su origen en un deseo erótico infantil. Para poderlo revivir, Hannold tuvo que hacer un largo rodeo cuyo trayecto se inició en el momento en que desplegó un interés apasionado por el relieve, del que se enamoró aun y cuando se tratara de un objeto inanimado, que además representaba a una joven muerta. Para que Hannold pudiese amar a Zoe, ésta ha tenido que ser Gradiva y habitar en las regiones subterráneas sepultada por la lava. Su presencia real no atemorizó al arqueólogo, durante los primeros encuentros, porque creyó que se trataba de una aparición. 
Pero no hay que olvidar, que el hecho de que un ser humano, principalmente si es artista, se enamore de una obra de arte, encuentra su paradigma en el mito de Pigmaleón, que logra dotar de vida humana a una creación suya, si bien en este caso el enamoramiento no es más que una prolongación narcisista de la libido autoerótica, en tanto el sujeto de amor es una obra propia. No por ello hay que descartar el enamoramiento, también real, hacia otros objetos. Muchos estetas y coleccionistas acusan intensas fijaciones afectivas hacia un determinado producto artístico, y éste es uno de los factores que apuntalan el diagnóstico de Freud de la siguiente manera:

"El psiquiatra incluiría quizá la perturbación de Hannold en el amplio grupo de las paranoias y la calificaría de erotomanía fetichista -no sólo en cuanto a la fijación por el objeto inanimado, sino también, y en forma importante porque el pie de Gradiva es el rasgo de más sobresaliente atractivo en el conjunto de la obra-; pero - sigue comentando Freud- no hay que olvidar que todas esas calificaciones y divisiones del delirio, basadas en el contenido del mismo, son harto inseguras e inútiles." En esta frase yo veo una proyección suya muy característica. Por una parte, le repugnaban los (artistas) lunáticos, en la misma medida en que sentía cierta aversión por los enfermos sicóticos en cuanto pensaba que no eran muy susceptibles de ser tratados sicoanalíticamente. Por eso minimiza la importancia del delirio fetichista de Hannold, indentificándose en este sentido no sólo con él sino también con Gradiva, quien lo ve confuso, pero susceptible de recobrar la claridad, por lo que se lanza a destruirle poco a poco las fantasías delirantes instaurándolo en la realidad como si ella fuera una sicoterapeuta.

Respecto al fetichismo, Freud añade que "todos los investigadores de estas materias atribuimos la génesis fetichista a impresiones eróticas de la infancia". Pero aunque tal desviación de la libido tenga realmente ese origen, no hay que olvidar que al incluir dicha peculiaridad en el carácter de su personaje, el autor está tomando un elemento que es muy común a gran parte de la prosa y la plástica de su época. Los pies y el pelo son elementos intensamente eróticos en un número considerable de obras decimonónicas. Por ejemplo, Gustave Flaubert dedica varias páginas a describir las botitas y las medias que usaba Madamme Bovary, y lo hace en varias escenas de la novela. 
Freud analiza tres sueños del protagonista y da poca importancia a uno más, quizá por ser el único que no se refiere directamente a Gradiva. Como es un sueño interesante desde el punto de vista de su contenido iconográfico, voy a referirme a él, aventurando una interpretación.

Hannold se encuentra pasando la noche en una posada de Roma, ciudad donde habrá de permanecer muy poco tiempo, ya que sus motivaciones inconscientes lo llevarán pronto a Pompeya. Antes de dormir presta atención al diálogo que sostiene una pareja de recién casados en la habitación contigua. Las palabras que se dicen los amantes no le producen una impresión tan molesta como la que se ha apoderado de él ante el espectáculo de numerosísimas parejas de recién casados que deambulaban por Italia en viaje de bodas. Sueña esa noche lo siguiente, según relata Jensen:

El sueño volvió a situarlo en Pompeya, justamente en los momentos en que volvía a entrar en erupción el Vesubio. Un hormiguero de personas se apretujaban a su derredor y entre ellas vio de repente al Apolo del Belvedere que alzaba en sus brazos a la Venus Capitolina, llevándosela y poniéndola a salvo mientras la depositaba en un objeto situado en un lugar oscuro.

Las estatuas, curiosamente, no hablaban en griego, sino en alemán. A mi modo de ver el sueño está ciertamente condicionado por el diálogo que escuchó en la noche, pero a la vez se relaciona con un hecho que sucede de páginas después. Ya en Pompeya, Hannold conoce a una pareja que conversa ante una botella de vino, se trata de un joven y una muchacha que se comunican en alemán, son guapos y simpáticos y "no se asemejan a otras parejas de recién casados, más bien parecen hermanos".

En la mitología, Apolo y Venus son medios hermanos en cuanto a que ambos son hijos de Zeus. Por otra parte, las dos esculturas helenísticas: el Apolo del Belvedere y la Venus Capitolina, son también hermanas desde el ángulo estilístico. Además, representan entidades complementarias. Apolo es el sol, la razón, la sabiduría y el arte. Venus el amor, la belleza, la voluptuosidad y la fecundidad. Por eso aparecen juntas en tantas representaciones alegóricas simbolizando atributos deseables entre los humanos. De hecho constituyen un par con cualidades complementarias ideales. Apolo colo- 
ca a Venus sobre un objeto oscuro, o sea que la prepara para la relación sexual.

El sueño de Hannold tuvo un carácter premonitorio que le hizo posible comprender - a través de frías estatuas- que el matrimonio podía no ser "el peor de los desastres", en tal forma que lo predispuso no sólo a encontrar simpática a la pareja del restaurante, sino a percibirla ligada por vínculos fraternales. Esto último le permitió aceptarla positivamente en ese primer encuentro y tiempo después desarrolló la capacidad, totalmente inusual en él, de interesarse en contemplar una tierna escena amorosa entre ellos que lo reconcilia con Eros, al grado de que se siente inundado de una extraña dicha:

Sus ojos (de Hannold), no podían despegarse de ese cuadro vivo, tal como nunca le había sucedido con ninguna obra de arte antiguo, por mucho que la admirara.

La fascinación por el arte cede paso a la fascinación por lo real, produciéndose el desplazamiento de la libido, dirigida otrora exclusivamente al símbolo o a la representación. Éstos sirven de trampolín, mediante el sueño de Roma, para que el desplazamiento pueda efectuarse.

En la última parte de su estudio, Freud hace una analogía entre el procedimiento que utiliza Gradiva para despertar a Hannold de su delirio y el método analítico utilizado por él en sicoterapia. Sin embargo, ya para terminar, hace una observación que muestra su grado de objetividad, aun ante aquello que le fascina:

Claro es que el caso de Gradiva es un caso ideal, que la ténica médica no puede jamás alcanzar. Gradiva puede corresponder al amor que ha logrado llevar desde lo inconsciente a la conciencia, cosa que al médico le está vedada.

Para llegar a esta conclusión, Freud ha revisado previamente el problema de la transferencia, por lo que su estudio ofrece una síntesis autosuficiente del sicoanálisis aplicado, síntesis que desde un punto de vista literario supera, y con mucho, el lenguaje algo alambicado del autor de la novela. 
En ningún momento olvida Freud que la carga libidinosa hacia el relieve constituye en sí un amor real, lo que también queda expresado por la fusión de los dos componentes principales del primer sueño relatado por Jensen: Hannold sueña que Gradiva muere en Pompeya el día de la erupción del Vesubio. Dado que todo soñante protagoniza su sueño, Hannold no sólo descubre la identidad de Gradiva, sino puede a la vez contemplar la catástrofe. $Y$, como dice Freud, "iqué no daría un arqueólogo por haber sido testigo presencial de la catástrofe que sepultó Pompeya!" El estudio termina con un párrafo contundente que vincula la interpretación de Gradiva con el somero análisis sobre el cuadro de Tiziano a que me he referido páginas atrás. "Pero debemos detenernos aquí, pues nos encontramos a punto de olvidar que Hannold y Gradiva no son sino entes de ficción creados por el poeta." Estas líneas, escritas en 1907, pueden servir de introducción crítica a la aproximación de Freud al Moisés de Miguel Angel.

Desde el punto de vista interpretativo, el Moisés de Miguel Ángel es el menos afortunado de los ensayos de Freud, aunque a la vez sea uno de los más ilustrativos acerca de su personalidad y de su método de aproximación.

La figura de Moisés tenía una larga historia en la vida de Freud. Es bien sabido que se sentía vinculado con la imagen del patriarca hebreo que no llegó a poner los pies en la tierra prometida. Anteriormente también se habia identificado con Aníbal y esto ocurrió cuando en uno de sus viajes a Italia, anteriores a 1901, se dio cuenta de que a pesar de su fascinación por Roma, nunca había llegado más allá del lago Trasimeno. En 1901 rompió las resistencias que le impedían visitar la ciudad papal y ese viaje constituyó para él un punto cúspide en su vida, puesto que vio realizado uno de sus más grandes anhelos. A partir de entonces volvió a Roma varias veces, pero fue durante ese primer viaje cuando realizó sus primeras visitas diarias a la iglesia de San Pietro in Vincoli, con el objeto de ver la tumba de Julio II. No emitió por entonces ningún comentario. Su correspondencia sólo registra que entraba a la iglesia y contemplaba al Moisés.

Cuatro años antes de escribir el ensayo sobre esta escultura, Freud había escrito su bellísimo estudio sobre Leonardo. Esta elección 
también obedecía a una identificación. El Leonardo contiene uno de los mejores "autorretratos" de Freud. ${ }^{16}$

El Moisés de Miguel Angel fue redactado durante los mismos meses en que Freud escribió dos estudios en los que anuncia las divergencias existentes entre sus puntos de vista y los de quien por varios años fue su predilecto y más prometedor discípulo: Carl Gustav Jung. Dichos trabajos llevan por título: "Sobre el narcisismo" e "Historia del movimiento sicoanalítico". Fueron publicados respectivamente en 1913 y 1914 y escritos, al igual que el Moisés, durante el otoño de 1912.

En el mes de septiembre de ese año, Freud había pasado sus vacaciones en Roma, donde permaneció tres semanas. Desde allí comunicó a su familia que nuevamente había visitado San Pietro in Vincoli día con día. Ya para entonces albergaba el proyecto de escribir algo acerca de la estatua. El trabajo fue iniciado durante los meses que siguieron a su regreso a Viena.

Siguiendo un esquema que Freud utilizó en la mayor parte de sus trabajos sobre sicoanálisis aplicado, antes de entrar en materia explica su postura en relación al tema que va a tratar, y a continuación indica las premisas sobre las que basa su análisis. El texto comienza con las siguientes palabras: "He de confesar, ante todo, que soy profano en cualidades formales o técnicas, a las que el artista concede en cambio la mayor importancia." Líneas después afirma que: "Una disposición racionalista o acaso analítica se rebela en mí contra la posibilidad de emocionarme sin saber por qué lo estoy y qué es lo que me emociona." 17

A su juicio, la obra de arte emociona porque a través de ella es posible aprehender la intención del artista en cuanto él mismo ha logrado trasmitirla a la obra haciéndola inteligible al espectador. Si la obra es "eficiente", tiene que facilitar ese análisis, puesto que "como expresión que es, comunica las intenciones y los impulsos del artista".

Habría mucho que discutir sobre esta valoración estética basada en un factor de eficiencia para comunicar intenciones. Sólo quiero hacer notar que el empleo del término "eficiencia", en relación a un producto artístico, es actualmente muy empleado por la crítica

16 Se recomienda Ia lectura del excelente texto de Meyer Schapiro, "Leonardo and Freud". Journal of the History of Ideas, vol. 17, num. 4. Londres, 1968.

It Sigmund Freud, "El Moisés de Miguel Ángel", en Obras completas, t. Ir. 
de arte de raigambre estructuralista, como también resulta concordante con este tipo de pensamiento la reflexión de que la obra misma contiene intrínsecamente sus posibilidades de análisis.

Estas frases tal vez harán pensar al lector que Freud encaró su estudio sobre el Moisés sin más armas que su propio método. Pero no ocurrió así y en este sentido el ensayo que ahora comento representa el opuesto a su trabajo sobre Gradiva, en el que el texto funciona como referente único. El Moisés de Miguel Ángel contiene citas textuales y referencias a no menos de veinte autores, entre ellos los siguientes: Giorgio Vasari, Ascanio Condivi, Jacobo Burckhardt, Carl Justi, Henry Thode, Wilhelm Lübke, Hermann Grimm, Heinrich Wolfflin, Fritz Knapp, W. Waltkers Lloyd e Ivan Lermolieff, un médico y crítico de arte italiano cuyo verdadero nombre era Morelli. Sus trabajos, que impresionaron en forma singular a Freud, llegaron a provocar una gran inquietud en el medio artístico de la Europa de fines de siglo, debido a que estableció la identidad de muchos cuadros, antes sólo atribuidos a tal o cual artista, echando a la vez por tierra no pocas atribuciones que resultaron falsas. Lograba sus resultados prescindiendo de tal impresión de conjunto que presentaba la obra y acentuando la importancia de los detalles secundarios, tales como la forma de representar las uñas, el pabellón de la oreja, y otras minucias que los copistas descuidan imitar y que todo artista ejecuta en una forma que le es característica. A juicio de Freud, el método de Morelli mostraba grandes afinidades con el sicoanálisis. "También el sicoanálisis acostumbra deducir de rasgos poco estimados o inobservados, del residuo -el refuse- de la observación, cosas secretas o encubiertas." 18

Siguiendo este método, Freud centró su análisis principalmente en la observación e interpretación de tres rasgos: el movimiento contenido de las piernas, la posición de la mano derecha en relación a las Tablas de la Ley y la trayectoria de la barba. Pero antes de dar su propia descripción sobre la estatua, y sobre estos elementos que le inquietaron particularmente, hace una crítica en la que ex. plica los errores y contradicciones que encontró en las descripciones hechas por otros autores. También pone particular énfasis en señalar que la postura de la pierna izquierda se flexiona conno- 
tando un movimiento que se va a iniciar, o bien, que ha sids) reprimido en el último momento. Al poner en relación esta peculiaridad potencialmente dinámica, con la trayectoria de la barba, la posición del dedo índice que desvía algunas greñas de su dixección normal, y la postura del otro brazo en relación a las Tablas, Freud se encamina a apuntalar una hipótesis que constituye el meollo interpretativo de su estudio: Moisés no va a levantarse y a romper las Tablas de la Ley, ante el espectáculo que le presenta el pueblo judío adorando al becerro de oro. Su impulso colérico inicial ha sido dominado y por eso permanece sentado, domada su furia. "No arrojará ya las tablas quebrándolas contra la piedra, pues precisamente a causa de ellas ha dominado su ira, refrenando para salvarlas su apasionado impulso."

Según esta interpretación, Miguel Ángel no representó un momento histórico tomado del Exodo, sino que imprimió una actitud atemporal a la estatua, y la causa de ello debe verse en la situación conflictiva de sus relaciones anteriores con Julio II, las que como se sabe, fueron cordiales cuando el activo pontífice, que pretendía nada menos que la unificación de Italia cuatro siglos antes de que ésta se hubiera realizado, encargó a Miguel Ángel el proyecto y la ejecución de su sepulcro que debió ocupar el crucero de San Pedro.

¿Con qué objeto representó así Miguel Ángel a Moisés? Según Freud, con el objeto de eternizarlo como salvador de las Tablas de la Ley. Al igual que en el caso del Leonardo, Freud está nuevamente escribiendo sobre sí mismo, pero en esta ocasión tiene dudas -muy justificadas- sobre la yuxtaposición de sus propias intenciones con las de Miguel Ángel.

No confío nada en la claridad de mi descripción, ni quiero aventurar juicio alguno sobre si el artista nos ha hecho fácil la solución del indicado remolino de la barba... Quizá estos pequeños detalles no significan nada en el fondo, y estamos fatigando nuestro pensamiento con cosas que al artista le eran indiferentes.

Sin embargo, no acepta que la disposición de la barba y los motivos a que obedece, puedan referirse únicamente "sa razones de línea y espacio".

Las dudas sobre su interpretación del Moisés se reafirman con un hecho que resulta indispensable tener en cuenta: es el único 
escrito de Freud publicado en forma anónima. Cuando sus amigos y discípulos le inquirieron el motivo por el cual se rehusaba a firmarlo, demostrándole, además, que de todas maneras su estilo lo delataría, dio las siguentes respuestas:

A Sandor Ferenczi: "¿Para qué deshonrar a Moisés agregándole mi nombre?... Se trata de una broma -aunque tal vez no sea mala."

A Karl Abraham: "No me siento seguro respecto al carácter de aficionado que tiene el artículo."

A Otto Rank: "Las dudas que albergo acerca de mis conclusiones es más intensa que de costumbre. No habría consentido en publicarlo siquiera, si no fuera por la presión editorial." ${ }^{19}$

Con el pintor Hermann Struck, que hacia noviembre de 1914 se encontraba terminando un retrato suyo, es aún más explícito y contundente:

Tengo muchas ganas de recibir los comentarios que me prometió sobre el Moisés de Miguel Ángel (se refiere a la estatua, no a su ensayo). Como no han llegado aún, no quiero seguir aplazando la devolución de las pruebas ni la redacción de esta carta. Me apresuro a decirle aun antes de oír sus comentarios, que me doy cuenta de la debilidad radical que preside este trabajo mío. Procede del intento de evaluar al artista en forma racional, como si fuera un erudito o un técnico, cuando, en realidad, se trata de un ser de categoria especial, exaltado, autocrático, villano y a veces bastante incomprensible, 20

Freud, en realidad, no evaluó al artista sino a través de unas supuestas intenciones deducidas de la excelencia de la obra. Pero aunque la tesis que sostiene sea efectivamente débil, el trabajo es una espléndida exposición de un método de análisis que en mucho se asemeja al de Panovsky. Fue una fortuna que se diera esa "presión editorial" de la que habla; de lo contrario el escrito tal vez se hubiera perdido, como quizá aconteció con el texto sobre la demencia de la emperatriz Carlota de México, que en lo personal nunca he visto publicado, aunque sí existen datos de que fue leido por el mismo Freud en una conferencia.

Muchos años más tarde, en 1933, Freud escribió al editor de la traducción italiana del Moisés, Edoardo Weiss, que lo que sentía por este trabajo:

19 Ernest Jones, op. cit., t. II.

20 Epistolario, t. II. Carta a Hermann Struck escrita el 7 de noviembre de 1914. 
Se parece mucho al sentimiento que inspira un hijo natural... Todos los días durante tres semanas me paré frente a la estatua, la medía, hacía croquis, hasta que capté su sentido, que sólo en forma anónima me aventuré a expresar. Muchos años más tarde he reconocido a esta creatura no analítica. ${ }^{21}$

A los setenta y siete años, cuando sus teorías eran, si no universalmente aceptadas, sí universalmente conocidas, Freud podía decir que había "captado el sentido" de la estatua. Esta afirmación contradice sus anteriores dudas. Sin embargo, tiene una explicación. Exactamente por esas fechas se encontraba enfrascado en la realización de lo que sería su última obra importante: Moisés y el monoteismo, fascinante texto en el que una de las tesis que se sostienen es que Moisés no era israelí, sino egipcio, factor que sirve de puntal para la elaboración de una trama singularmente rica que -pese a lo discutible de la hipótesis en que se basatiene un valor filosófico y sociológico incalculable para la comprensión de problemas relacionados con la religión, la autoridad y la ley.

Volviendo al texto sobre la estatua. Las razones por las que la interpretación de Freud respecto al movimiento reprimido no son sostenibles, están referidas a los rasgos posturales complicados y los detalles artificiosos con los que Miguel Ángel dotaba a sus figuras desde 1508, aproximadamente, en adelante. La estructura de estas figuras describe, tanto en su totalidad como en sus partes, movimientos en espiral que forman la línea serpentinata que en Miguel Ángel aparece casi en forma sistemática a partir de la decoración de la bóveda de la Capilla Sixtina, donde es posible encontrar varias imágenes que ostentan posturas parangonables a la del Moisés. Nos encontramos ante problemas formales que Miguel Ángel, incansable investigador del cuerpo humano como motivo formal per $s e$, se planteó muy tempranamente siguiendo un impulso anticlásico, que habría de situarlo como al máximo exponente e instaurador del manierismo. El contrapunto que ofrece el mechón de la barba del Moisés, desviándose de derecha a izquierda, con el de la pierna flexionada, sólo puede ser aquilatado en el contexto mismo de la obra de Miguel Angel. Recordemos que, con variantes, se presenta también en otra impresionante escultura sedente que acusa también como

21 Epistolario, t. II. Carta a Edoardo Weiss escrita el 12 de abril de 1933 
rasgo típico la impresión de un movimiento en potencia: la escultura que representa a Giuliano de Medici de la capilla funeraria de los Medici en Florencia.

El Moisés de San Pietro in Vincoli funde los rasgos de Julio II con los del propio Miguel Ángel, quien casi autodidacta, autoritario y consciente de su genio; quizá también identificó aspectos personales suyos con aquella rabia sagrada de que fue presa el padre del pueblo judío. En este sentido, estoy dando en parte la razón a Freud, pero sólo en parte, puesto que en ningún momento hay que olvidar que el escultor, además de que seguía un plan iconográfico preconcebido, que había sido alterado por falta de cumplimiento de sus patrocinadores, obedecía, como ha quedado asentado, a problemas de forma, volumen y composición.

Pero si Freud no proporcionó una interpretación del todo convincente acerca de la estatua de Miguel Ángel, su texto revela un estricto proceder de crítico de arte. No sólo por la índole del material bibliográfico y hemerográfico que empleó para apuntalar su análisis, sino también porque -al enfrentamiento visual con la escultura- añadió croquis y dibujos (por cierto desaparecidos), a la vez que acuciosas consideraciones acerca del emplazamiento de la pieza en relación con las que se acompañan, como asimismo un cotejo muy bien observado con algunas copias, a su parecer inexactas, que existen de la escultura.

Tiempo después de publicado el estudio, Ernest Jones proporcionó a Freud un número del Burlington Magazine ${ }^{22}$ que contenía un artículo en el que el crítico H. P. Mitchell compara esta obra con dos piezas existentes en el Ashmolean Museum de Oxford, atribuidas a un escultor del siglo xII: Nicolas de Verdum. En una reedición muy posterior de El Moisés de Miguel Angel, aparece un pequeño apéndice en el que Freud incluye la información obtenida. Termina con estas palabras:

Quizá algún crítico de arte pueda llenar el intervalo temporal entre el Moisés de Nicolas de Verdum y el del maestro del Renacimiento Italiano con la indicación de otros tipos de Moisés intermedios.

Este deseo, expresado en forma por demás sencilla, es típico de quien no queda conforme ni siquiera con el hallazgo de un material

22 Burlington Magazine for Conoisseurs, núm " ccxviI, vol. xxxvir, abril de 1821. 
que viene a apuntalar su tesis. El problema, para Freud, quedó abierto. Nunca consideró tener la última palabra, ni en este caso, ni en ningún otro.

Como conclusión a esta aproximación a las actitudes de Freud frente al arte, nada mejor que terminar con estas palabras suyas tomadas de El malestar en la cultura: "El goce de la belleza no tiene utilidad evidente, $\mathrm{ni}$ es manifiesta su necesidad cultural, sin embargo, la cultura no podría prescindir de ella."

Febrero de 1979

A cuarenta años de la muerte de Sigmund Freud. 